Articles

\title{
Toward a Sociocultural Learning Theory Framework to Designing Online learning Communities in Citizen Science
}

Ruth Kermish-Allen

Kate Kastelein
Maine Mathematics and Science Alliance, United States

Corresponding Author.

rkermishallen@gmail.com

Maine Mathematics and Science Alliance, United States

kkastelein@mmsa.org

How can sociocultural learning theory inform design principles for citizen science online learning communities to inspire local environmental action? The purpose of this article is to identify themes in sociocultural learning theory that could inform the use and development of highly collaborative online learning communities that utilize community informatics tools for citizen science to enable on-the-ground environmental actions. Applying previously established sociocultural theories provides an opportunity to build on what's already known about how people learn and collaborate. Finally, this article explains how communities of practice theory, knowledge building theory, and place-based education theory can be woven together to create the basis for development of a conceptual framework.

Kermish-Allen, R., Kastelein, K. (2017). Toward a Sociocultural Learning Theory Framework to Designing Online learning Communities in Citizen Science. The Journal of Community Informatics, 13(3), 4-19.

Date submitted: 2017-11-02. Date accepted: 2017-12-15.

Copyright (C), 2017 (the author as stated). Licensed under the Creative Commons AttributionNonCommercial-ShareAlike 2.5. Available at: www.ci-journal.net/index.php/ciej/article/view/1424 


\section{Introduction}

People want to learn with technology, with one another, in their own time, in their own place, and do things that matter (Fadel \& Lemke, 2006). To meet this demand, new digital opportunities have quickly worked their way into educational contexts. People around the globe are using new tools within community informatics to understand their environments better and share those understandings as they exponentially amplify connections across the globe (Dickinson, Bonney, Fitzpatrick \& Louv, 2012). For example, community activists in Peru are connecting with scientists in Pennsylvania via online communities to learn about new methods to determine the amount of lead and other chemicals in drinking water near resource gas extraction sites. Indigenous students in Alaska are connecting with climate scientists to document changes in the sea ice at villages where their families have lived for generations.

Citizen science is a fast-growing sector of informal science education that is working hard to leverage global connectivity and improve the health and sustainability of communities. Citizen science originated as a way for the general public to assist scientists in collecting data for their research, as well as a vehicle to communicate aspects of science to the general public (Bonney, Ballard, Jordan, \& McCallie, 2009). But what do the citizens get in return? How can the citizen and his or her community be seen more as a partner and beneficiary in citizen science projects? A project has the potential to go beyond learning about the monarch butterfly, for example. Instead it can bring people together to understand how their region relates to the butterfly's migration routes and life cycle, as well as what they can do in their everyday lives to address the problems facing the monarch and the ecosystems upon which it depends.

Learning theory plays a very important role in the realization of the vision for citizen science described above. Within the field of community informatics, applying existing theory to a new platform, such as an online citizen science community, plays a key role in providing greater understanding to what we already know about technology in online communities (Willams \& Durrance, 2008). Timothy Kochmann (1996) coined the term computer-supported collaborative learning (CSCL), to define a new educational paradigm which focuses on the use of technology as a tool within collaborative methods of instruction. As stated by Dennen \& Hoadley (2013, p. 392):

"The design of CSCL is not to define a specific learning theory or content domain to be covered and the optimal way to cover it...instead CSCL instructional theories often specify roles, norms, values, or other process oriented aspects of the learning environment. The CSCL designer gives up control of many instructional choices that would be normal in the traditional design of non-collaborative environments - in exchange the designer can tap into powerful (if unpredictable) social processes to help drive learning."

In this spirit of adventure, the purpose of this article is to identify themes in educational theory (cognitive and instructional) that could inform the use and development of highly 
collaborative online learning communities for citizen science. This theoretical exploration will offer thoughtful research-based guidance to designing strategies that link the fields of community informatics with citizen science to inform the design of online communities with the goal of placing power into the hands of those who need it most, the citizen scientists and community members looking for answers to local questions.

To accomplish this goal the article will first provide an exploration of the tenets of Vygotsky's sociocultural learning theory as well as more contemporary perspectives. Next, the article delves into the applications of sociocultural theory in related instructional theories such as: Wenger's Communities of Practice (CoP) (Lave \& Wenger, 1991; Wenger, 2000b), Scardamalia and Beretier's Knowledge Building Theory (Scardamalia \& Bereiter, 2006), Gonzalez and Moll's Funds of Knowledge (Gonzalez, Moll, \& Amanti, 2005; Moll, Amanti, Neff, \& Gonzalez, 1992), and Sobel's Place-based education (Gruenewald \& Smith, 2008; Sobel, 2005). 


\section{Linking Sociocultural Education Theory with Citizen Science}

Collaborative and co-created variants (Bonney, Ballard, Jordan, McCallie, Phillips, Shirk \& Wilderman, 2009) of citizen science align well with sociocultural learning theory due to the strong recognition and value of cultural and historical perspectives that individual participants can bring to the study. Vygotskian sociocultural approaches are based on the concept that human activities take place in cultural contexts and are mediated by tools, language, and other symbols that can be best understood when investigated in their cultural and historical settings (Kozulin, Gindis, Ageyev, \& Miller, 2003). Sociocultural perspectives on learning have many common threads including: 1) the importance of tools, both socially and culturally constructed; 2) the need for a diverse social circle, including lesser and more experienced individuals; and 3) pedagogies and contexts that respect cultural and historical perspectives (John-Steiner \& Mahn, 1996).

Sociocultural learning theory moves away from the norm of learning as an individual enterprise and instead places emphasis on the social processes of the co-construction of knowledge (Tobin, 2014). From a sociocultural perspective, an individual is always closely related to the social spheres and groups within which he or she functions, thus the goals of an individual are closely related to the group's motives and purpose (Tobin, 2012). Therefore, productive learning environments foster opportunities for individuals who not only act for themselves but also promote their own achievement to expand the learning of others (Tobin, 2014). This approach to learning favors a co-production model characterized by a redistribution of the traditional roles of participation in the production of scientific knowledge (Cook, 2015).

Co-created and collaborative forms of citizen science build upon sociocultural learning theory as projects ask participants to not only gather data but also revise data collection protocols (in partnership with scientists) to fit within cultural norms. In some instances, projects provide the opportunity for participants to ask their own questions related to the local contexts in which participants live. When projects take this approach they are gaining the benefit of local social and historical contexts to make the overall project goal relevant to the learner and his or her community. For example, a sociocultural perspective would challenge individuals involved in study with the goal of increasing the frequency of the identification of new or invasive species in a key fishery's ecosystem to work closely with the communities that depend on that fishery - valuing and respecting their cultural norms, incorporating their values and traditional knowledge into data collection methods, and asking them for assistance in the interpretation of findings and recommendations for increasing populations.

Sociocultural theory also provides insight into the design and use of technologymediated learning environments, such as online contexts. Using a socio-cultural approach to develop online learning communities provides a lens for investigating the interconnectedness between the individual and social spheres mediated by modern technology (Bencze \& Alsop, 2014). Applying these understandings provides a platform to build on what we already know about how people learn and collaborate to guide the 
development of effective online citizen science communities. Empowering communities and individuals to ask their own scientific questions, using new tools to understand their environments better, sharing those understandings with a broad audience, and amplifying connections across the globe (Mueller, Tippins \& Bryan, 2012) as those involved build healthier and more sustainable communities (Jenkins, 2011).

This article explores four variants of sociocultural learning theories that provide solid ground upon which to build a new framework for collaborative online learning in citizen science. Communities of practice theory, knowledge building theory, place-based education theory, and funds of knowledge theory are all discussed in detail. This article will first introduce each theory and then describe theory-driven design principles for online communities, to provide design principles and integrate concepts from all four theories for the basis of a conceptual framework.

\section{Communities of Practice Theory}

A Community of Practice (CoP), as defined by Lave and Wenger (2000), is any group of individuals working in relation with each other and the world through a shared set of practices to accomplish a shared enterprise or goal (Lave \& Wenger, 1991). The theory's main assumption is that learning occurs through social participation (Wenger, 2000a). Participation in this sense refers not just to being engaged in local events with specific people, but to a more all-encompassing process of becoming active participants in the practices of social communities and construction of identities in relation to those communities (Wenger, 2000b). Kisiel (2010) expanded on these ideas with the introduction of intersecting CoPs that bring together various CoPs to develop new goals together utilizing a combination of each CoP's original shared practices. There are many questions in science that cannot be answered by one $\mathrm{CoP}$ alone.

Citizen science projects have the potential to leverage both the CoP and intersecting $\mathrm{CoP}$ models to advance scientific and educational goals. As the problems our communities face become more complex, the assumption that individuals can solve a problem alone, or the "expert as savior" mentality, has melted away. It is becoming clearer that we need CoPs that are continually building knowledge together to learn from the past mistakes of others to share all possible resources to combat the problems at hand. Utilizing an online based citizen science system can link members of communities that may not normally interact with each other. By building relationships between a diverse range of community members, a collective sense of community power may be established (Stoecker, 2005).

Examples of this are often seen in understanding and mitigating the impacts of climate change on fishing communities, for instance. Scientists have realized that they need the traditional knowledge, expertise, and access that generational fisherman have to the populations and fishing grounds. At the same time, fishermen acknowledge that the marine ecosystem they know and love is changing and they need the partnership of the scientific community to understand these changes and develop their industry around sustainable practices that will ensure their livelihoods. 
Some basic design principles emerge from this exploration and critique of $\mathrm{CoP}$ that could be built upon to develop online learning communities - they are shared below:

1. Online learning communities (OLC) should connect individuals who have a shared repertoire - use the same resources (same tools, artifacts, experiences, definitions) to accomplish the shared goals of the community (Hoadley \& Kilner, 2005).

2. The goals and/or requirements of the online learning community should be defined and negotiated informally by members of the OLC - an example of joint enterprise (Hoadley \& Kilner, 2005).

3. The overlapping purpose or joint enterprise of the citizen science OLC should unite, motivate, and, in part, validate the activities of the OLC as significant. (Barab \& Duffy, 2000).

4. Having a defined central purpose of the OLC can provide a starting ground from where members can begin to develop relationships and take on roles within the OLC (Hoadley \& Kilner, 2005).

5. OLCs should provide tools and associated practices that the community needs to solve an authentic, real-world problem (Jonassen \& Land, 2012).

6. Both novices and experts should be valued in the OLC (Barab \& Duffy, 2000).

7. OLCs can provide opportunities for mutual engagement, referring to actions and especially interactions which members of the community share (Wenger, 2000b).

8. OLCs should provide a shared repository of information resources that are used by the community in its practices (Roschelle, Pea, Hoadley, Gordin, \& Means, 2000).

CoP as an instructional theory provides a magnificent basis upon which to build online learning communities for citizen science, but it does not go far enough. For example, $\mathrm{CoP}$ theory refers to learning as a linear process that moves along a continuum from novice to expert, as in the apprenticeship model from which CoP theory emerged. This is an important aspect of learning, but it does not value multi-directional learning in which the apprentice can also provide learning experiences for the mentor. A citizen science example of multi-directional learning could be when a local fisherman shares knowledge of where a specific species of interest can normally be found with a scientist known as an expert in the species. Furthermore, CoP theory only places emphasis on groups that already have a shared repertoire as they use the same resources (same tools, artifacts, experiences, definitions) to accomplish the shared goals of the community. $\mathrm{CoP}$ theory does not discuss the rich learning experiences that occur when groups of people that do not have a shared repertoire come together and work toward a common goal. The recognition of this gap is an outstanding opportunity to advance CoP theory. Researchers such as Kisiel (2010) are beginning to enter into this gap to offer alternatives such as intersecting CoPs which value bringing together multiple CoPs to solve a problem across a variety of shared repertoires. 
Lastly, in the CoP model, theorists state that most CoPs have a shared repository of the knowledge for that community. This component, of course, is necessary to a successful $\mathrm{CoP}$ as seen in indigenous or traditional cultures that use multiple methods to store and share traditional knowledge. This concept is not new and has been shared from generation to generation over millennia. Shared repositories are not static but ever changing as evolving members of the CoP critique, refine, and use the knowledge of the $\mathrm{CoP}$ in new and more productive ways. Through the technological capabilities we have available to us today we can modernize this concept and share these forms of knowledge with communities across the globe. These expansions of CoP theory provide the groundwork for a new framework which builds off of the strengths and potential new applications of CoPs. Knowledge building theory, which is a variant of CoPs, provides greater emphasis on the actual mechanics of how knowledge is created rather than how it is shared.

\section{Knowledge Building Theory}

Knowledge building - the creation of knowledge as a social product - is something that scientists, scholars, and employees of highly innovative companies do for a living (Bereiter, 2005). Knowledge Building (KB) theory, defined by Scardamalia and Bereiter (1994), is a particular kind of community of practice that has the explicit goal of developing individual and collective understanding (Hoadley \& Kilner, 2005). KB should not be confused with knowledge dissemination, which is defined as the transfer of knowledge across settings. There is an area of overlap between knowledge dissemination and $\mathrm{KB}$, but that distinction is not central to the purpose of this article and KB's role. In short, knowledge dissemination is the process of sharing knowledge from an individual entity to others.

$\mathrm{KB}$ is built upon: 1) a shared commitment of the community to generate new knowledge; 2) the importance of discourse; 3) the ability to build upon past knowledge, ideas, and artifacts; 4) shared responsibilities across the community for collaboration and decision-making; and 5) the importance of new and emerging sub-goals (Zhang, Scardamalia, Reeve, \& Messina, 2009). Knowledge building represents an attempt to re-invent formal education to initiate students into a knowledge creating culture, involving learners not only developing knowledge building competencies but also coming to see themselves and their work as part of the civilization wide effort to advance knowledge (Scardamalia \& Bereiter, 2006). Scardamalia and her colleagues (Hewitt \& Scardamalia, 1998; Oshima, Scardamalia, \& Bereiter, 1996; Zhang et al., 2009) have further defined four essential design principles, or opportunities for engagement, that must be present for knowledge building communities to function:

1. Collective Cognitive Responsibility requires taking responsibility for the state of public knowledge (Zhang et al., 2009), anticipating and identifying challenges and solving problems, and collectively defining knowledge goals as they emerge throughout the process. 
2. Awareness of Contributions implies that there is a collective responsibility to knowing the 'from where' and 'from whom' information, actions, and goals have emerged, as well as understanding the changing goals, situations, actions, and connections in a community (Zhang et al., 2009).

3. Complementary Contributions (Zhang, 2009) respond to and build upon one another's ideas (Palincsar, Anderson, \& David, 1993) and contribute nonredundant and important information that advances the pursuit of knowledge as a whole.

4. Distributed Engagement (Zhang et al, 2009) provides a framework for highlevel operations such as community coordination, goal setting, and decision making to be completed across the entire community with minimal hierarchical control.

Knowledge building has strong core principles defining how knowledge is built in a $\mathrm{CoP}$ and is rooted in the power and ability of learners (specifically students) to truly advance knowledge in society. But it does not explain the interactions between overlapping communities, such as exchanges among inter-generational or multiple stakeholder-based communities. This opens up the opportunity for a new form of knowledge building community, one that reaches outside the boundaries of the classroom to include members of the greater community in knowledge building.

This essential theme of bringing groups together to build knowledge is paramount in the realm of citizen science. Citizen science hopes to partner the goals and research questions of the scientific community with the large numbers and interests of the general public. Additionally, citizen science aims to answer scientific questions that cannot be answered by one discipline alone, but depend upon the coming together of many areas of expertise and ways of knowing. Therefore, the question becomes, how can design principles for online communities in citizen science foster and value multiple stakeholder perspectives? To address this question, an interwoven conceptual framework should build upon learning theories that place particular emphasis on the expertise of the learners themselves and how their life experiences can be extremely valuable assets to a learning community.

\section{Funds of Knowledge}

Funds of Knowledge (FoK) theory places emphasis on historically accumulated and culturally developed bodies of knowledge and skills essential for survival, success, and well-being (Gonzalez et al., 2005; Moll et al., 1992). In Moll's (1992) investigations into knowledge exchange in immigrant communities she found that each household held accumulated bodies of knowledge based on the family members' life experiences, including agricultural, socio-political, and historical knowledge. The methods for knowledge transfer in the home and community setting was in stark contrast to the experiences of the community's youth in the formal classroom. FoK theory investigates how this accumulated knowledge from life experiences can provide value and meaning for formal and informal learning experiences (Gonzalez et al., 2005). The findings of Moll and her colleagues identified strategies for how families develop social networks 
that interconnect them with their social environments and how those relationships share and build new knowledge, information and resources related to a households' ability to survive and thrive in sometimes very difficult situations (Moll et al., 1992). These same strategies could prove very useful in the exchange of information and knowledge building between diverse stakeholder groups, such as those in citizen science. In these settings, sharing individuals' funds of knowledge can accomplish the shared goal of the group. Moll's core concepts provide valuable insight for potential design elements in online learning communities for citizen science:

1. Place value on each individual's historically accumulated and culturally developed body of knowledge and skills - fund of knowledge (Gonzalez et al., 2005).

2. Provide opportunities for community member to interact in adaptive, flexible, multi-dimensional ways to encourage multiple forms of relationships between individuals (Moll et al., 1992).

3. Provide opportunities for connections between members to become reciprocal and build trust over time instead of becoming buried at the end of an activity feed (Moll et al., 1992).

Citizen science projects ask participants to share components of their individual fund of knowledge based on where they live and what they see around them every day. An example is India's People's Biodiversity Register that asks residents to share historical and current information on dwindling numbers of the Siberian crane or the Vital Signs project's request for local gardeners to share their historical understanding and current knowledge of invasive plant species in their region.

FoK theory can provide insight into design elements that illicit local traditional knowledge from individuals who may not necessarily see that know-how as important or beneficial to the scientific community, when in fact that information can be more powerful than any expensive monitoring device. In addition, the questions posed by citizen science projects are usually inter-disciplinary in nature. Therefore, citizen science communities will be comprised of individuals or stakeholder groups that may not naturally seek each other out. FoK theory can contribute greatly to the development of both design and instructional elements for citizen science projects. The marriage of ideas between citizen science and FoK could prove useful in accomplishing the goals of the citizen science field, especially locally driven initiatives.

\section{Place-based Education}

The application of funds of knowledge usually occur in a specific place, for example the knowledge built up over generations about how to respond to periods of drought in local farming regions. The construct of place is very important when contextualizing this type of knowledge. Place-based education theory provides guidance for how to structure learning experiences grounded in questions of place. Place-based Education (PBE) promotes interdisciplinary learning rooted in the local community to accomplish both academic- and civic- engagement goals, while at the same time providing learners with 
the experiences and confidence to believe that they can influence positive change in their communities (Gruenewald \& Smith, 2008; Smith \& Sobel, 2010; Sobel, 2005). Designers of successful classroom interventions must make sure they are engaging enough to seduce learners into the world of learning (Brown, 1992). PBE takes this advice to heart by engaging most actively in topics that are framed with a high level of personal relevance and authenticity (Sobel, 2005).

PBE begins locally and answers questions that are relevant to that community. Learning environments present core concepts through a locally-framed lens, leading to high levels of ownership and engagement (Chawla \& Cushing, 2007a). Accomplishing the civic and academic goals of PBE requires a great deal of skill development, specifically around problem solving, communication and collaboration. It is not enough for learners to learn beliefs and values about what they should do, they need opportunities to learn what they can do (Chawla \& Cushing, 2007b). The key to PBE is that participants are learning about how they can influence their own community and see the change that they are capable of bringing about through partnerships with other groups in the community.

PBE fits squarely within a sociocultural paradigm as it provides guidance for how to apply learning concepts in a locally relevant way. Duffin and colleagues (2008) reviewed educational literature and reported six core qualities essential to PBE that can serve as design principles for online learning communities in citizen science:

1. Focus on topics that are relevant to learners;

2. Involve experiential and hands-on activities;

3. Promote understanding of concepts;

4. Use the local environment as a context for learning;

5. Learners work individually and in groups; and

6. Incorporate project-based work;

The focus on influencing locally relevant problems and questions fits perfectly with citizen science, since one of the goals of citizen science is to gain access to local data across a very large geographical span with the aid of locally trained volunteers. PBE by nature is small in scale and locally contained. An opportunity for growth within PBE lies in partnering the power of online environments with the power of local questions. Many of today's environmental challenges have the potential to unite learners from around the world, if they have access to each other. Community informatics provides insights from online citizen science communities which may be utilized to improve a number of areas including sustainability, educational, and economic issues (Eagle, Hague, Keeble, \& Loader, 2005) Studies of invasive species, for example, or farming in drought conditions, provide the opportunity to connect with others trying to find solutions to similar problems.

However this is only possible if the online communication tools we have available to us today are brought to the forefront. Together individuals in online communities learn how to combat the issue in question through sharing experiences of their own place. In 
many situations, such as climate change, solutions to the problems being faced by local communities cannot be understood or solved without the complex coordination of many different communities (and places) sharing what they are experiencing and what their strategies for solutions are. Online communities for citizen science may provide a vehicle with which to meet this goal of starting with the local and reaching out across a much wider distributed population. In addition, incorporating PBE with online communities will provide new opportunities for learners to get out into their world and gain access to new places across the globe that they would not have experienced otherwise.

\section{Developing a Conceptual Framework}

Socio-cultural theory provides an established basis from which a conceptual framework can be built. Communities of Practice (CoP) focuses on how a group of individuals work and learn together. Integration of CoP theory helps inform how an online community might function. Place-based education (PBE) links the work of the community to the relevant interests and place of the participants. Knowledge Building $(\mathrm{KB})$ guides the community with the intention to build new knowledge together related to the citizen science question mind. Funds of Knowledge (FoK) provide the framework with guidance for how to value diverse lived experiences and not just the "usually suspected" forms of expertise. This conceptual framework incorporates diverse participant groups, real-world investigations rooted in place (local contexts), valuing lived experience as essential to building new knowledge, a recognition that knowledge generation is not a top-down process but instead a dynamic multi-directional process between participants, and finally leveraging the power of a digital culture to build a knowledge-building community that transcends geographic limitations of traditional place-based education to answer questions people care about.

Image 1 below summarizes the key ideas and design principles in each of the targeted sociocultural instructional theories explored. When looked at as a whole, we can begin to see core themes emerge. For example, the recognition of diverse participant groups is clearly present in both Funds of Knowledge (FoK) and Place-based Education (PBE) instructional theories. Have a shared a shared purpose of the learning community with user-defined goals or sub-goals is a strong theme across CoP, Knowledge Building $(\mathrm{KB})$, and PBE. When looked at as a patchwork or interwoven quilt working together we see a a conceptual framework emerge - the Non-Hierarchical Online Learning Communities conceptual framework.

"Non-hierarchical," in this sense, is defined as a collaborative learning forum in which traditional experts, such as scientists are no longer perceived as the sole owners and creators of knowledge. Instead, all participants are generators of content and knowledge as well as active learners; the boundaries between scientist and citizen, young and old are blurred into one cohesive community of actively engaged learners. 


\section{Image 1: Summary of the NHOLC Conceptual Framework}

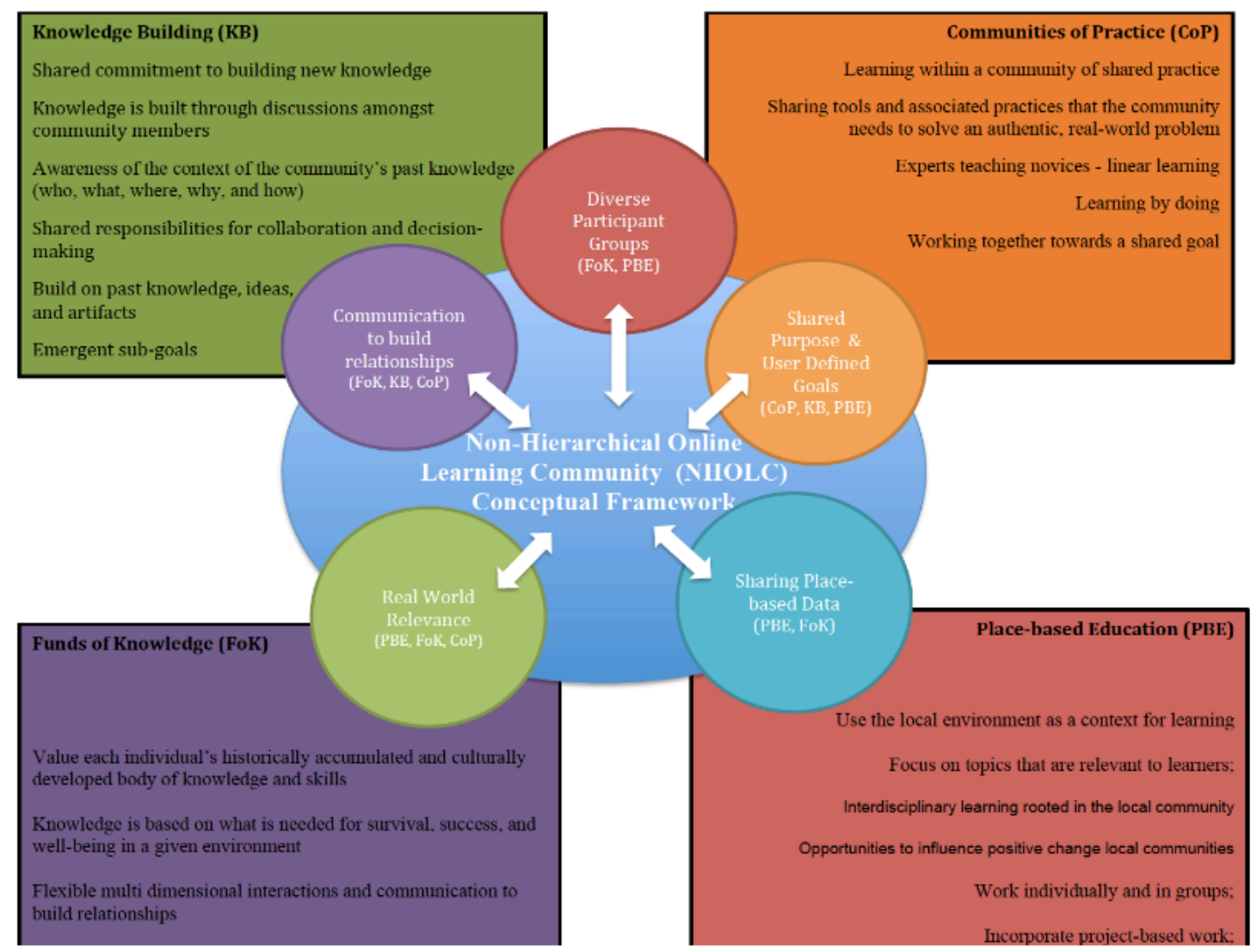

This interwoven framework places emphasis on:

1. Bringing together diverse participant groups from widely differing areas of expertise to enable multi-directional learning opportunities in which everyone that joins the community has something they can offer and teach others within the community

2. Enabling participant-driven real-world investigations that are personally relevant to participants' lives

3. Sharing project purpose and goals

4. Enabling communication structures to build relationships and roles amongst a diversity of participants

5. Sharing place-based data across geographic boundaries

\section{Conclusion}

Through this exploration of sociocultural learning and instructional theories the NHOLC framework has been developed in the hopes of providing learning theory-based guidance to the citizen science field in the design of online learning communities for citizen science. This framework, targeted at supporting collaboration is specifically 
designed to support more of the collaborative and co-created variants of citizen science gaining momentum in the world. As more and more individuals and communities throughout the world gain access to the digitally connected world, we can now leverage that connectivity to support change and action initiatives that matter to people where they live. We can bring together groups of people that would otherwise never have had the opportunity to learn from each other. A common goal may now bring together adversaries in a less-contentious online space to work together.

There are still many unanswered questions, such as: does the NHOLC framework match up to existing examples of successful collaborative online citizen science communities; does one aspect of the NHOLC carry more weight than the others when working toward achieving collaboration; does the NHOLC framework match with the experiences of online citizen science community members? It is the hope and purpose of this theoretical exploration to offer thoughtful research-based guidance to find innovative strategies to link the field of community informatics with citizen science to inform the design of online communities with the goal of placing power into the hands of those who need it most: the citizen scientists and community members looking for answers to local questions.

\section{References}

Barab, S. A., \& Duffy, T. (2000). From practice fields to communities of practice. In Theoretical Foundations of Learning Environments (pp. 25-55).

Bencze, L., \& Alsop, S. (2014). Activist Science and Technology Education (2014 edition). Springer.

Bonney, R., Ballard, H. L., Jordan, R., \& McCallie, E. (2009). Public Participation in Scientific Research: Defining the Field and assessing Its Potential for Informal Science Education. A CAISE Inquiry Group Report. Center for Advancement of Informal Science Education (CAISE).

Brown, A. L. (1992). Design Experiments: Theoretical and Methodological Challenges in Creating Complex Interventions in Classroom Settings. The Journal of the Learning Sciences, 2(2), 141-178.

Chawla, L., \& Cushing, D. F. (2007a). Education for Strategic Environmental Behavior. Environmental Education Research, 13(4), 437-452.

Chawla, L., \& Cushing, D. F. (2007b). Education for strategic environmental behavior. Environmental Education Research, 13(4), 437-452. https://doi.org/ 10.1080/13504620701581539

Conover, S., Kermish-Allen, R., \& Snyder, R. (2014). Communities for Rural Education, Stewardship, and Technology (CREST): A Rural Model for Teacher Professional Development. In J. MaKinster, N. Trautmann, \& M. Barnett (Eds.), Teaching Science and Investigating Environmental Issues with Geospatial Technology (pp. 139-152). Springer Netherlands. Retrieved from http://link.springer.com/chapter/ 10.1007/978-90-481-3931-6_9

Cook, K. (2015). Democratic Participation with Scientists Through Socioscientific Inquiry. In M. P. Mueller \& D. J. Tippins (Eds.), EcoJustice, Citizen Science and Youth Activism 
(pp. 281-295). Springer International Publishing. https://doi.org/ 10.1007/978-3-319-11608-2_17

Dickinson, J. L., Bonney, R., Fitzpatrick, J. W., \& Louv, R. (2012). Citizen Science: Public Participation in Environmental Research (1 edition). Ithaca: Comstock Publishing Associates.

Duffin, M., Murphy, M., \& Johnson, B. (2008). Quantifying a relationship between place-based learning and environmental quality: Final Report. Conservation Study Institute.

Eagle, D., Hague, B., Keeble, L., \& Loader, B. D. (2005). Community Informatics: Shaping Computer-Mediated Social Networks. Routledge.

Fadel, C., \& Lemke, C. (2006). Technology in schools: What the research says. Gonzalez, N., Moll, L. C., \& Amanti, C. (Eds.). (2005). Funds of Knowledge: Theorizing Practices in Households, Communities, and Classrooms (1 edition). Mahwah, N.J: Routledge.

Gruenewald, D. A., \& Smith, G. A. (2008). Place-based education in the global age: local diversity. New York: Lawrence Erlbaum Associates.

Hart, R. A. (1997). Children's Participation: The Theory and Practice of Involving Young Citizens in Community Development and Environmental Care. Routledge.

Hewitt, J., \& Scardamalia, M. (1998). Design Principles for Distributed Knowledge Building Processes. Educational Psychology Review, 10(1), 75-96. https://doi.org/10.1023/A: 1022810231840

Hoadley, C. M., \& Kilner, P. G. (2005). Using Technology to Transform Communities of Practice into Knowledge-building Communities. SIGGROUP Bull., 25(1), 31-40. https://doi.org/10.1145/1067699.1067705

Jenkins, L. (2011). Using citizen science beyond teaching science content: a strategy for making science relevant to students' lives. Cultural Studies of Science Education, 6(2), 501508. https://doi.org/10.1007/s11422-010-9304-4

John-Steiner, V., \& Mahn, H. (1996). Sociocultural approaches to learning and development: A Vygotskian framework. Educational Psychologist, 31(3-4), 191-206. https://doi.org/ $10.1080 / 00461520.1996 .9653266$

Jonassen, D., \& Land, S. (Eds.). (2012). Theoretical Foundations of Learning Environments (2nd ed.). Routledge.

Kermish-Allen, R., Peterman, K., Macdonald, S., Thompson, R., \& Winner, B. (2015). Student and Teacher Teams Using High Resolution Electricity Monitoring to Create Local Change. The Journal of Sustainability Education, January 2015.

Kisiel, J. (2012). Reframing Collaborations with Informal Science Institutions. In D. Ash, J. Rahm, \& L. M. Melber (Eds.), Putting Theory into Practice (pp. 55-75).

SensePublishers. Retrieved from http://link.springer.com/chapter/ 10.1007/978-94-6091-964-0_6

Kisiel, J. F. (2010). Exploring a school-aquarium collaboration: An intersection of communities of practice. Science Education, 94(1), 95-121. https://doi.org/10.1002/sce.20350

Koschmann, T. D. (1996). CSCL, Theory and Practice of an Emerging Paradigm. Routledge.

Kozulin, A. (2002). Psychological Tools: A Sociocultural Approach to Education. Cambridge, Mass.: Harvard University Press.

Kozulin, A., Gindis, B., Ageyev, V. S., \& Miller, S. M. (2003). Vygotsky's Educational Theory in Cultural Context. UK ; New York: Cambridge University Press. 
Lave, J., \& Wenger, E. (1991). Situated Learning: Legitimate Peripheral Participation (1st edition). Cambridge England; New York: Cambridge University Press.

Louv, R. (2012). The Nature Principle: Human Restoration and the End of Nature-Deficit Disorder. Algonquin Books.

Moll, L. C., Amanti, C., Neff, D., \& Gonzalez, N. (1992). Funds of knowledge for teaching: Using a qualitative approach to connect homes and classrooms. Theory Into Practice, 31(2), 132-141. https://doi.org/10.1080/00405849209543534

Mueller, M., Tippins, D., \& Bryan, L. (2012). The Future of Citizen Science. Democracy \& Education, 20(1), 1-12.

Oshima, J., Scardamalia, M., \& Bereiter, C. (1996). Collaborative learning processes associated with high and low conceptual progress. Instructional Science, 24(2), 125-155. https:// doi.org/10.1007/BF00120486

Palincsar, A. S., Anderson, C., \& David, Y. M. (1993). Pursuing Scientific Literacy in the Middle Grades Through Collaborative Problem Solving. The Elementary School Journal, 93(5), 643-658.

Roschelle, J. M., Pea, R. D., Hoadley, C. M., Gordin, D. N., \& Means, B. M. (2000). Changing how and what children learn in school with computer-based technologies. The Future of Children, 76-101.

Scardamalia, M., \& Bereiter, C. (1994). Computer Support for Knowledge-Building Communities. Journal of the Learning Sciences, 3(3), 265-283. https://doi.org/10.1207/ s15327809j1s0303_3

Scardamalia, M., \& Bereiter, C. (2006). Knowledge building: Theory, pedagogy, and technology. The Cambridge Handbook of the Learning Sciences, 97-115.

Smith, A., G. ,.(Author),Sobel, D. ,.(Author), \& Sobel, D. (2010). Gregory A. Smith,David Sobel'sPlace- and Community-Based Education in Schools (Sociocultural, Political, and Historical Studies in Education) [Hardcover](2010) (1 edition edition). Routledge.

Sobel, D. (2005). Place-based education: connecting classrooms \& communities. Great Barrington, MA: Orion Society.

Stoecker, R. R. (2005). Is Community Informatics Good for Communities? Questions Confronting an Emerging Field. The Journal of Community Informatics, 1(3). Retrieved from http://www.cijournal.net/index.php/ciej/article/view/183

Tobin, K. (2012). Sociocultural Perspectives on Science Education. In B. J. Fraser, K. Tobin, \& C. J. McRobbie (Eds.), Second International Handbook of Science Education (pp. 317). Springer Netherlands. https://doi.org/10.1007/978-1-4020-9041-7_1

Tobin, K. (2014). Using Collaborative Inquiry to Better Understand Teaching and Learning. In L. Bencze \& S. Alsop (Eds.), Activist Science and Technology Education (pp. 127-147). Springer Netherlands. https://doi.org/10.1007/978-94-007-4360-1_8

Vygotsky, L. S. (1980). Mind in Society: The Development of Higher Psychological Processes. (M. Cole, V. John-Steiner, S. Scribner, \& E. Souberman, Eds.) (New Ed edition). Cambridge: Harvard University Press.

Wenger, E. (2000a). Communities of Practice and Social Learning Systems. Organization, 7(2), 225-246. https://doi.org/10.1177/135050840072002

Wenger, E. (2000b). Communities of Practice: Learning, Meaning, and Identity (1 edition). Cambridge, U.K.; New York, N.Y.: Cambridge University Press. 
Wertsch, J. V. (1985). VYGOTSKY AND THE SOCIAL FORMATION OF MIND. Harvard University Press.

Williams, K., \& Durrance, J. C. (2008). Social Networks and Social Capital: Rethinking Theory in Community Informatics. The Journal of Community Informatics, 4(3). Retrieved from http://www.ci-journal.net/index.php/ciej/article/view/465

Zhang, J., Scardamalia, M., Reeve, R., \& Messina, R. (2009). Designs for Collective Cognitive Responsibility in Knowledge-Building Communities. Journal of the Learning Sciences, 18(1), 7-44. https://doi.org/10.1080/10508400802581676 